2017-04-01

Calibration and response of an agarose gel based passive sampler to record short pulses of aquatic organic pollutants

\title{
Belles, A
}

http://hdl.handle.net/10026.1/9403

10.1016/j.talanta.2016.12.010

Talanta

All content in PEARL is protected by copyright law. Author manuscripts are made available in accordance with publisher policies. Please cite only the published version using the details provided on the item record or document. In the absence of an open licence (e.g. Creative Commons), permissions for further reuse of content should be sought from the publisher or author. 


\section{Calibration and response of an agarose gel based passive sampler}

\section{2 to record short pulses of aquatic organic pollutants}

3

Angel BELLES ${ }^{a} *$, Claire ALARY ${ }^{b, c}$, Yann AMINOT ${ }^{d}$, James W. READMAN ${ }^{d}$, Christine $^{-}$ FRANKE $^{a}$

${ }^{a}$ MINES ParisTech, PSL Research University, GEOSCIENCES - Centre for geosciences and geoengineering, 35 rue St. Honoré, F-77305 Fontainebleau Cedex, France

${ }^{b}$ Mines Douai, LGCGE-GCE, F-59508 Douai, France

${ }^{c}$ Univ. Lille, F-59500 Lille, France

${ }^{d}$ Biogeochemistry Research Centre, Plymouth University, PL48AA Plymouth, United-Kingdom

\section{ABSTRACT}

A passive sampler inspired from previous devices was developed for the integrative sampling of a broad range of contaminants in the water column. Our primary objective was to improve the performance of the device to provide accurate and averaged pollutant water concentrations. For this purpose, an agarose diffusive gel was used as the boundary layer that drives the analyte uptake rate. Contrary to conventional passive samplers, the developed device does not require the sampling rates to be corrected for exposure conditions (e.g. hydrodynamic flow) because the diffusive gel boundary layer selected was sufficiently large to control the pollutant diffusion rate from the aqueous phase. The compounds diffusion coefficients in agarose gel and the gel thickness are the only required data to accurately calculate the time weighted averaged water concentration of pollutants. The performance of the developed sampler was evaluated in the laboratory under two contamination scenarios and in the field in 8 contrasting exposure sites for a selection of 16 emerging pollutants and pesticides. The results show that detection limits of this method are environmentally relevant and allow the determination of the averaged pollutant concentrations. Additionally, the ability of the device to sense 
very short contamination pulses (5 to $320 \mathrm{~min}$ ) was evaluated through a theoretical approach and laboratory tests. Results show that the device is suitable for sampling contamination pulses as short as 5 min without deviation from the actual average concentrations of pollutants.

\section{KEYWORDS}

Passive sampler; polar contaminant; agarose gel; contamination pulse; water

\section{HIGHLIGHTS}

A novel agarose gel-based passive sampler was developed for polar pollutants

The compounds uptake rates do not depend on water flow conditions

The devices are able to accurately record very short contamination pulses $(<10 \mathrm{~min})$

The sampling rates determined in laboratory are suitable for field exposure

\section{INTRODUCTION}

One of the main advantages of water passive samplers is their integrative sampling giving access to a time weighted averaged (TWA) water concentration over its exposure period. This averaged water concentration is a suitable indicator for compliance monitoring of regulated substances, such as in the European Water Framework Directive. However, the use of samplers in their integrative regime for determining the TWA concentration requires maintenance of the pollutant accumulation far from equilibrium between the water and the samplers and to evaluate the uptake rate of compounds in the passive samplers (Lohman et al. 2012). Unfortunately, many studies report the exposure condition-dependence of the uptake rate leading to difficulties in deriving the TWA water concentration (O'Brien et al. 2012; Chang et al. 2015). To correct the sampling rate for the environmental conditions, such as hydrodynamic flow or temperature, a performance reference compounds (PRC) approach was successfully developed for partitioning-based passive samplers (e.g. SPMD, polymeric passive samplers) (Booij et al. 1998, Belles et al. 2016a). Problems arise, however, 
when sampling relatively polar compounds for which such devices have limited affinities.

Alternatively, numerous studies have demonstrated the ability of sorbent-based passive samplers (e.g. POCIS, Chemcatcher) to efficiently trap the more polar compounds unsuitable for the partitioningbased passive samplers (Bailly et al. 2013; Charriau et al. 2016; Vrana et al. 2016). However, reliable quantitative TWA water concentrations are difficult to achieve as with the partitioning-based passive samplers, the uptake rates of such devices are highly dependent on the exposure conditions (Li et al. 2010; Belles et al. 2014a). Unlike the partitioning-based passive samplers, however, the PRC approach should not be implemented to improve the quantitative reliability of the sorbent-based devices because they are driven by surface sorption processes rather than partitioning (Harman et al. 2011; Liu et al. 2013). Typically, the hydrodynamic flow is by far the most critical parameter driving the uptake rate of the sorbent-based passive samplers by controlling the thickness of the stagnant water film at the samplers surface, the so called water boundary layer (WBL) (Li et al. 2010; Belles et al. 2014a; Carpinteiro et al. 2016). In this context, the development of samplers with a kinetic accumulation that is not controlled by the compound diffusion through the WBL is a promising evolution of passive sampler tools for accurately deriving the TWA water concentration of the polar pollutants without needing a hydrodynamic flow correction for compound uptake rate (Garcia-Rodríguez et al. 2016). The strategy introduced by Chen et al. $(2012,2013,2015)$ aimed at reducing the compound uptake rate by adding a diffusion step through a gel layer of known thickness. Ultimately, the process of mass transfer through the diffusive gel is the limiting process and controls the uptake rate. The kinetic of accumulation is then expected to be independent of the hydrodynamic flow and the uptake rate measured in laboratory conditions should be close to the field values. This strategy was first successfully applied by Chen et al. $(2012,2013,2015)$ for waste water treatment plants by using an agarose gel diffusing layer in the DGT housing leading to a small sampling surface area $\left(3.14 \mathrm{~cm}^{2}\right)$ at the expense of sensitivity. Similar devices were tested by Fauvelle et al. (2014) through a set of laboratory experiments for the sampling of polar and ionic pesticides. However two questions remain: is the performance of such devices environmentally relevant for trace level analyses? How do such devices integrate contamination pulses? 
the measurement of TWA water concentrations by improving its detection limit and its integrative sampling ability including the case of short contamination pulses. Firstly, the devices were calibrated in the laboratory by measuring the diffusion coefficients of the targeted compounds in the agarose gel and by measuring the actual uptake rates of compounds in the whole samplers immersed in water under various exposure conditions. The sampler's ability for sensing short contamination pulses was then theoretically evaluated and measured under laboratory conditions. Finally, the devices were tested through various field exposures for examining their environmental robustness.

\section{MATERIALS AND METHODS}

\subsection{Chemicals}

Standards of target compounds and labeled internal standards (listed in Table 1 and S1) were supplied by Sigma Aldrich (France) and LGC standards (United-Kingdom). All solvents and chemicals were of analytical grade or better (Fisher Scientific, France). Strata-X polymeric reversed phase $(30 \mu \mathrm{m})$ was obtained from $500 \mathrm{mg}$-solid phase extraction (SPE) cartridges (Phenomenex, United-Kingdom). Low electro-endosmosis agarose powder (for molecular biology (3,6-Anhydro- $\alpha$-Lgalacto- $\beta$-galactan) and glass petri dishes (used as sampler bodies) were provided by Sigma Aldrich (France). Gel strength for a $1 \%$ agarose gel $(\mathrm{w} / \mathrm{w})$ is $1200 \mathrm{~g} / \mathrm{cm}^{2}$, the gelling point for $1.5 \%$ gel $(\mathrm{w} / \mathrm{w})$ is $36+/-1.5^{\circ} \mathrm{C}$ and the sulfate content of the dried powder is below $0.15 \%$.Prior to use, all glassware was combusted for $12 \mathrm{~h}$ at $400{ }^{\circ} \mathrm{C}$. The Strata $\mathrm{X}$ sorbent was cleaned by passing $10 \mathrm{~mL}$ of dichloromethane (DCM) through the SPE cartridges under vacuum.

\subsection{Passive sampler design and kinetic accumulation model}

The designed devices used a receiving medium consisting of Strata-X reversed phase sorbent immobilized in agarose gel which is separated from the sampled water only by a $1.2 \mathrm{~mm}$ diffusive layer of unfilled agarose gel (Figure 1). To improve the predictability of the kinetic exchange between the device and the sampled water, no additional membranes were used to protect the diffusive gel (Vermeirssen et al. 2012). The diffusion coefficient of pollutants in agarose gel is expected to be lower 
than in water (Pluen et al. 1999) and the $1.2 \mathrm{~mm}$ gel thickness is several times higher than the typical WBL thickness which ranges between 10 and $1000 \mu$ m (Huckins et al. 2006; Belles et al. 2016b). Both properties ensure that the mass transfer through the diffusive gel layer is slower than across the WBL so that the compounds uptake rate should be fully controlled by the diffusive gel. Because the gel is an un-convectional diffusive medium, for which the thickness is not dependent on the hydrodynamic flow, the uptake rates measured in the laboratory are expected to be the same than in the field providing that other parameters do not affect the kinetics of accumulation (e.g. temperature).

Owing to the affinity of compounds for the Strata-X sorbent, the concentration in the diffusive gel at its interface with the binding gel, where diffusing compounds emerge is maintained effectively at a null concentration. In this case, Crank et al. (1975) found that the compound accumulated in the binding gel $(M, \mathrm{ng})$ is a function of the water concentration $\left(C_{w} ; \mathrm{ng} \mathrm{mL} L^{-1}\right)$, the surface exchange area $\left(A ; \mathrm{cm}^{2}\right)$, the thickness of the diffusive gel $(\delta ; \mathrm{cm})$ and the diffusion coefficient in agarose gel $\left(D_{g e l}\right.$; $\left.\mathrm{cm}^{2} \mathrm{~s}^{-1}\right)$

$$
C_{w}=\frac{M \delta}{D_{g e l} A t}
$$

Equation 1 is a useful indicator for a long exposure time and was adopted by several authors in the field of passive samplers (Addeck et al. 2012; Chen et al. 2013; Fauvelle et al. 2014). If we consider the early stage of accumulation kinetics, e.g. for studying the passive sampler's response to a very short contamination pulse, it makes more sense to consider the general equation (Equation 2) for kinetic uptake (Crank et al. 1975):

$$
M=\delta C_{w} A\left(\frac{D_{g e l} t}{\delta^{2}}-\frac{1}{6}-\frac{2}{\pi^{2}} \sum_{n=1}^{\infty} \frac{(-1)^{n}}{n^{2}} \exp \left(-\frac{D_{g e l} n^{2} \pi^{2} t}{\delta^{2}}\right)\right)
$$

Equation 2 takes into account the transient stage for establishment of the steady state flow rate of compounds through the diffusive gel (commonly called "lag phase"), leading to a delay in the effective compound accumulation (Huckins et al. 2006). Usually, the characteristic time needed to achieve the steady state flow rate is expressed as the intercept on the time-axis of the accumulation curve given by Equation 3:

$$
t_{l a g}=\frac{\delta^{2}}{6 D_{g e l}}
$$




\subsection{Passive sampler preparation}

Passive samplers were built in the bottom half of a glass petri dish $(11.5 \mathrm{~cm}$ internal diameter $)$ by successive deposition of a $0.7 \mathrm{~mm}$-thick layer of binding gel and a $1.2 \mathrm{~mm}$-thick layer of diffusive gel (Figure 1). During the exposure of the samplers, both gels were held together with a plastic housing (acrylonitrile-butadiene-styrene) built using a 3D printer (MakerBot Replicator 2X) and protected with an aluminium screen (28\% open area; $12 \mathrm{Mesh})$. The binding gel was prepared by mixing $10 \mathrm{~mL}$ of water, $0.15 \mathrm{~g}$ of ultrapure agarose powder and $1 \mathrm{~g}$ of Strata-X sorbent. After homogenization, the preparation was heated in a water bath for 3 minutes, transferred into a pre-heated petri dish $\left(90^{\circ} \mathrm{C}\right)$ and left to cool at room temperature for $1 \mathrm{~h}$. Because $D_{g e l}$ depends to a large extent on the cooling rate during gelification, the cooling time and temperature were carefully controlled when preparing the passive samplers (Fatin-Rouge et al. 2004). Only the center part of the binding gel disk was kept by removing a $7 \mathrm{~mm}$ ring, resulting in a final sampling area of $78 \mathrm{~cm}^{2}$. The sampling surface of the designed device is significantly higher than the standard POCIS configuration which shows an exposure window of $46 \mathrm{~cm}^{2}$. POCIS also overestimates the effective sampling area owing to the surface of membrane which is not in contact with the POCIS sorbent (Fauvelle et al. 2014). After cooling of the binding gel, the diffusive gel ( $20 \mathrm{~mL}$ of water and $0.3 \mathrm{~g}$ of agarose powder; $1.5 \% \mathrm{w} / \mathrm{w}$ ) was cast in one time over the binding gel. The resulting diffusive gel thickness is of approximately 1.2 mm (Figure 1). After exposure of the passive samplers, the binding gel of each device was removed for analysis and the effective thicknesses of the diffusive gel $(\delta)$ were measured with a micrometer screw gauge for the calculation of the TWA water concentration (Equation 1).

\subsection{Determination of the compound diffusion coefficient in the agarose gel}

The diffusion coefficients in agarose gel of the target compounds were evaluated by the slice stacking method (Rusina et al. 2010, Thomson et al. 2015). Agarose gel disks of $2 \mathrm{~cm}$ diameter and 1 mm thickness were prepared as described previously for the diffusive gel of passive samplers by casting the warmed liquid agarose gel between 2 glass plates. After cooling, 15 disks were spiked by immersing them into $250 \mathrm{~mL}$ of water spiked at $2.5 \mathrm{mg} \mathrm{L}^{-1}$ with all selected chemicals. After $12 \mathrm{~h}$ of immersion, 9 spiked disk were retrieved and capped with 7 un-spiked disk each. The 6 last spiked 
disks were analysed as a blank for determining the initial compound concentrations (see section 2.9).

Three stacks were disassembled after a contact time of $5 \mathrm{~min}, 20 \mathrm{~min}$ and $2 \mathrm{~h}$, were extracted and each disk was analyzed separately. The diffusion coefficient $\left(D_{g e l}\right)$ was calculated for each contact time experiment by fitting the measured concentration in each disk of the stack with the model in Equation 4, derived from Crank et al. (1975):

$$
C=C_{0}\left(\frac{h}{l}+\frac{2}{\pi} \sum_{n=1}^{\infty} \frac{1}{n} \sin \left(\frac{n \pi h}{l}\right) \exp \left(-\frac{D_{g e l} n^{2} \pi^{2} t}{l^{2}}\right) \cos \left(\frac{n \pi x}{l}\right)\right)
$$

In Equation 4, $C\left(\mathrm{ng} \mathrm{g}^{-1}\right)$ is the compound concentration at the distance $x(\mathrm{~cm})$ from the top of the stack, $C_{0}\left(\mathrm{ng} \mathrm{g}^{-1}\right)$ is the measured initial contamination of the spiked disks, $h(\mathrm{~cm})$ is the total thickness of the stack, $l(\mathrm{~cm})$ is the thickness of the spiked disk, $t(\mathrm{~s})$ is the contact time and $n$ is the summation index. The measured $D_{g e l}$ were averaged for all contact time experiments where the final concentrations of the spiked disks are within the range 35-85\% of the initial concentrations (conditions of a significant concentration gradient). Outside this range, the values were discarded to minimize the uncertainty. In addition, the same experiments were conducted at $4{ }^{\circ} \mathrm{C}$ to evaluate the dependence of $D_{g e l}$ on temperature. Details of the $D_{g e l}$ values determined for each contact time experiment and the averaged numerical values are available in the supplemental data section (Table S2-S3).

\subsection{Strata-X to water sorption isotherms of compounds}

The sorption isotherms of selected compounds between the Strata-X sorbent and the water were determined by mixing $50 \mathrm{mg}$ of sorbent in 1 liter of contaminated water during a period of $15 \mathrm{~d}$. Nine contamination levels were simulated by adding to the aqueous phase 40, 100, 200, 400, 600, 2500, 10000, 20000 and $50000 \mu \mathrm{g}$ of each polar compound as a concentrated methanolic solution (3 order of magnitude are spanned). After the equilibration period, the sorbent and aqueous phases were separated by filtration through polypropylene frits (nominal pore size $0.7 \mu \mathrm{m}$ ) and separately analyzed.

\subsection{Laboratory calibration of the devices}


To ensure that the accumulation kinetics of compounds is fully controlled by the diffusion

across the gel and that $D_{g e l}$ is the only value required for calibrating the devices, the compound uptake rates by the samplers were measured in the laboratory through 2 experiments simulating different contamination sequences and hydrodynamic conditions. A first exposure simulated a constant water concentration $\left(5000 \mathrm{ng} \mathrm{L}^{-1}\right)$ and a strong water flow rate of $150 \mathrm{~cm} \mathrm{~s}^{-1}$ (estimated from the velocity of a float left in the experimental unit). A second condition simulated a low water flow rate $\left(20 \mathrm{~cm} \mathrm{~s}^{-1}\right)$ with a discontinuous water contamination composed of an initial 4 days of continuous contamination (1000 $\mathrm{n} \mathrm{L} \mathrm{L}^{-1}$ ) followed by 3 days with no contamination and 3 days of strongly contaminated water (5000 ng L ${ }^{-1}$ ). During the uncontaminated period, granular activated carbon was placed in the bottom of the experimental unit to keep the background water contamination close to zero (Thompson et al. 2015). In both experiments, the setting consisted of a $27 \mathrm{~L}$ exposure tank mixed with an overhead stirrer and contaminated by spiking water with a concentrated methanolic solution $\left(2 \mathrm{mg} \mathrm{L}^{-1}\right)$ to reach the target aqueous concentration. To keep the aqueous concentration constant, the water was renewed and spiked every day. For both experiments, 26 passive samplers were exposed in the water and 2 were retrieved once or twice a day. After exposure, the devices were rinsed with Milli-Q water and analyzed (see section 2.9). In addition, water samples of $800 \mathrm{~mL}$ from the experimental setting were collected at least every day and analyzed for monitoring the actual water concentration (see section 2.9).

\subsection{Response of the devices to a short contamination pulse}

The ability of the device to account for the contamination variability over a short contamination pulse was evaluated under laboratory conditions in moderately stirred water $\left(50 \mathrm{~cm} \mathrm{~s}^{-1}\right)$. For this purpose, 3 devices were exposed to un-contaminated water during 3 days including a brief immersion after $24 \mathrm{~h}$ in a second water tank contaminated with the target compounds listed in Table 1. The experiment was replicated for increasing contamination pulse periods of 5, 10, 20, 40, 80, 165 and 320 min. The water concentration during the contamination pulse periods was selected in order to expose all devices in all experiments to the same TWA water concentrations (i.e. 50, 28, 12.5, 6, 3, 1.5 and $\left.0.8 \mu \mathrm{g} \mathrm{L}^{-1}\right)$. For evaluating the actual water contamination, $1 \mathrm{~L}$ of water was sampled during the 
simulated contamination pulse for analysis (see section 2.9.). The shortest contamination pulse period was chosen in the order of the characteristic time needed to achieve the steady state flow rate through the agarose gel (Equation 3) assuming a $D_{g e l}$ value of $3.10^{-10} \mathrm{~m}^{2} \mathrm{~s}^{-1}$ (a common value for the considered compounds, see section 3.1).

\subsection{Field testing}

The field performance of the device for evaluating water contamination in contrasting exposure conditions was evaluated by exposing devices in 8 aquatic sites including: marine water, canals, lake and a waste water treatment plant. Details on the sample site properties are provided in Table S4. At each site, 3 devices were simultaneously exposed for a period ranging from 8 to 15 days. During the exposure period, at least 3 discrete water samples were collected for comparison to the TWA water concentration derived from the passive samplers. The water temperature was continuously monitored during the sampler exposure using a data logger (Onset HOBO data logger) and the conductivity and $\mathrm{pH}$ were measured at each discrete sample recovery.

\subsection{Analysis}

After filtration (GF/F; $0.7 \mu \mathrm{m})$, the collected water samples were spiked with an internal standard solution (Table S1) and treated by liquid-liquid extraction using 3 times $30 \mathrm{~mL}$ of dichloromethane as the organic extraction solvent. Recoveries of the extraction procedure were evaluated by analyzing 14 artificial samples consisting of $1 \mathrm{~L}$ of Milli-Q water spiked with 0.1 to $5 \mu \mathrm{g}$ of each target compound. Recovery rates for the target compounds ranged between $77 \%$ and $150 \%$ and the typical variability was of $\pm 20 \%$ (Table S5).

To extract the passive sampler devices, the Strata-X sorbent of the binding gel was recovered by freeze-drying the hydrated gel. Internal standards and $40 \mathrm{~mL}$ of dichloromethane were added to the dried sorbent. After $24 \mathrm{~h}$, the extract was collected and replaced by $40 \mathrm{~mL}$ of fresh dichloromethane and left for an additional 24 hours. Both extracts were combined and filtered thorugh $20 \mu \mathrm{m}$ PE frits.

The recovery rates of the passive sampler extraction procedure were examined by analyzing a third fraction of dichloromethane extracts for a set of 6 samples randomly selected. The average peak area 
of the compounds from the $3^{\text {rd }}$ fraction reached typically $1.5 \%$ of the signal area of the combined first 2 fractions, confirming the performance of the extraction procedure developed (Table S5).

The final products of the liquid-liquid extractions and of passive sampler extractions were blown down under a gentle stream of ultra-pure grade nitrogen at $55^{\circ} \mathrm{C}$ and the solvent was changed to $100 \mu \mathrm{L}$ of ethyl-acetate for the chromatographic analysis.

All extracts were analyzed by gas chromatography coupled to mass spectrometry detector (GC-MS; Agilent Technology 7890B series coupled to 5977 A mass spectrometer). One $\mu \mathrm{L}$ splitless was injected at $250^{\circ} \mathrm{C}$ on a $30 \mathrm{~m}$ column (HP5MS-UI $30 \mathrm{~m} \times 0.25 \mathrm{~mm}$ i.d. $\times 0.25 \mu \mathrm{m}$ film thickness) using Helium as a carrier gas at $1.3 \mathrm{~mL} \mathrm{~min}^{-1}$ (constant flow rate). The oven temperature programme was $55^{\circ} \mathrm{C}$ for $0.5 \mathrm{~min}$ and then increased at $10{ }^{\circ} \mathrm{C} / \mathrm{min}$ to a final temperature of $300{ }^{\circ} \mathrm{C}$, where it was held for $10 \mathrm{~min}$. The GC-MS transfer line temperature was set at $300^{\circ} \mathrm{C}$. The MS was operated in selected ion monitoring mode with electronic impact ionization with source temperature at $270{ }^{\circ} \mathrm{C}$ and quadrupole temperature at $150{ }^{\circ} \mathrm{C}$ (details of the characteristic ion monitored for each analyte are provided in Table S1).

Analyses of field control passive samplers showed no trace of any target compound $(n=3)$. Analysis of blanks of the liquid-liquid extraction procedures showed occasionally some traces of galaxolide, benzophenone, tris(phenyl)phosphate and octicizer and were subtracted as background from the corresponding field samples (Table S5).

\subsection{Diffusion coefficients in agarose gel}

An example of the galaxolide distribution over the gel stack after 5, 20 min and $2 \mathrm{~h}$ of contact time at $20{ }^{\circ} \mathrm{C}$ is shown in Figure 2. Similar distributions were observed for all of the selected compounds. $D_{g e l}$ was estimated by fitting the experimental points with Equation 4. Depending on the compounds, the measured diffusion coefficients ranged between -9.4 and -9.6 log unit $\left(\mathrm{m}^{2} \mathrm{~s}^{-1}\right)$ and the variability is typically $0.2 \log$ unit (factor 1.3). The measured diffusivities $D_{g e l}$ are in the order of the one measured for chlorpheniramine in $1 \%$ agarose gel at $25{ }^{\circ} \mathrm{C}\left(-9.26 \mathrm{~m}^{2} \mathrm{~s}^{-1} \log\right.$ unit), as reported by Sathynarayana et al. (1993). 
in the gel relative to the water $\left(D_{g e} / D_{w}\right)$, is a key parameter for characterizing the compounds mobility

(Partington et al. 1949):

$$
D_{w}=13.26 \frac{10^{-5}}{\eta^{1.4} V_{m}^{0.589}}
$$

A reduced diffusion coefficient below the unit $(\sigma<1)$ is typically observed in gel, because of a combination of chemical interactions with agarose polymer and steric factors. In this study, the hydrodynamic volume of selected compounds is too low for that steric interaction to prevail in the reduced diffusion coefficient. Effectively, assuming an average compound radius $\left(r_{s}\right)$ of $10 \AA$ and agarose fiber radius $\left(r_{s}\right)$ of $60 \mathrm{~nm}$, the obstruction model described by Johnson et al. (1996) $(\sigma=$ $\exp \left(-\Phi^{\frac{1}{2}} \cdot \frac{r_{s}}{r_{f}}\right)$; with $\Phi$ for the agarose volume fraction) predicts that the reduced diffusion coefficient should be about $99 \%$ in the presence of the steric interaction alone. By comparison, the experimentally measured $D_{g e l}$ gives an average reduced diffusion coefficient of $\sigma=62 \pm 9 \%$ which was for numerous compounds insignificant with respect to the error on the $D_{w}$ estimate ( $0.2 \log$ unit) and measured $D_{g e l}\left(\right.$ Table 1). Even though, according to the obstruction model, $D_{g e l}$ is expected to be equal to $D_{w}$, our results suggest that $D_{g e l}$ is lower than $D_{w}$, but due to the variability of the compared values we were not able to clearly provide evidence that $\sigma$ differs from unity. In addition, it should be noted that agarose gel is subject to H-bound interaction due to hydroxyl group and ionic interactions with charged groups, in particular pyruvate and sulfate which could reduce the mobility of some charged/polar compounds.

A significant temperature effect on $D_{g e l}$ was observed for all compounds with an average increase of $0.4 \log$ units (factor 2.5) between $4{ }^{\circ} \mathrm{C}$ and $20{ }^{\circ} \mathrm{C}$ (Figure 3, Table S2 and S3). This value is comparable to the one of the pharmaceutical ibuprofen which increases by a factor of 1.6 between 26 
and $45^{\circ} \mathrm{C}$ in $1 \%$ agarose gel (Sathynarayana et al. 1993). The temperature dependence of $D_{g e l}$ can be evaluated from an Arrhenius type relationship as:

$$
\ln D_{g e l T 1}-\ln D_{g e l T 2}=-\frac{E a}{R}\left(\frac{1}{T_{2}}-\frac{1}{T_{1}}\right)
$$

where $D_{\text {gel Tl }}$ and $D_{\text {gel T2 }}$ are the diffusivity at temperatures $T_{1}$ and $T_{2}, R\left(\mathrm{~kJ} \mathrm{~mol}^{-1} \mathrm{~K}^{-1}\right)$ is the gas constant and $E a\left(\mathrm{~kJ} \mathrm{~mol}^{-1}\right)$ is the apparent activation energy of compound diffusion within the gel.

The value of the $E a$ is a direct measurement of the temperature dependence of the compound diffusivity $D_{\text {gel }}$ (Table 1). Under our selected conditions, the average $E a$ was $47 \pm 14 \mathrm{~kJ} \mathrm{~mol}^{-1}$ which indicates that the diffusivity of compounds in agarose gel and subsequently the compounds uptake rate strongly depends on temperature, suggesting a variation by a factor 3.9 for typical field temperature values $\left(5-25^{\circ} \mathrm{C}\right)$.

\subsection{Laboratory calibration of passive sampler devices}

The time series of the amount of atrazine sampled by the devices in the two water flow conditions trialed in the laboratory experiments is given in Figure 4. For a direct comparison regardless of the difference in the water contamination levels, the results are given as the amount of compound sampled divided by the sampling surface area and the atrazine water concentration and further multiplied by the diffusive gel thickness (Equation 1). After normalization by the water concentration, the accumulated amounts of the compounds in both water flow conditions were similar. The hydrodynamic conditions do not affect the compounds uptake rate, confirming that it is driven by the diffusion across the diffusive gel rather than across the WBL (Li et al. 2010; Belles et al.2014b). This unique result illustrates the interest of our device in comparison to some other passive sampler configurations dedicated to the sampling of polar compounds (e.g. POCIS, Chemcatcher)..

$$
\text { An overview of atrazine kinetic uptake when devices were exposed to a discontinuous }
$$
contamination is given in Figure 5. For atrazine and all other target compounds in this study, the sampled amounts were directly proportional to the average water concentration indicating that the $D_{g e l}$ values are independent of the contamination level (Equation 1). Thus, the tested sampler is integrative 
and the final amount sampled by the device is consistent with the average water contamination. In

most cases, the sampled compounds are not significantly released from the device during the uncontaminated exposure period (analyses of water samples collected during the uncontaminated period confirmed that background contamination levels remained below the detection limits ). This underlines the ability of the samplers to integrate a contamination peak without losing the chemical information over the following exposure days. Compound release can become a problem when samplers are exposed to a lower water concentration during the last days of deployment as desorption will induce a loss of analytes and provide an underestimation of the TWA water contamination (Gourlay-Francé et al. 2008). In our study, only the most hydrophilic selected compounds (atrazinedesethyl; $\log \mathrm{P}=1.5 \pm 0.26$; XLOGP3 estimate (Cheng et al. 2007)) were significantly released during the 4 days of the uncontaminated water period with a sampled amount reduction of $13 \%$ (calculated as: sampled amount reduction=[initial concentration-final concentration]/initial concentration). Similar results were previously reported for POCIS passive samplers by Belles et al. (2014b) for a set of pesticides and pharmaceuticals with log P ranging between -1.7 and 2.0. By comparison, the usual partitioning-based passive samplers such as the polymeric sheets are more prone to compound release of similar hydrophobicity (Fluorene, Acenaphthene, Acenaphthylene and Naphthalene) for which full dissipation is common (Huckins et al. 2006; Belles et al. 2016b).

\subsection{Practical application of agarose gel based passive samplers}

$D_{g e l}$ are required for all compounds to estimate the TWA concentration in water from the amount of compounds sampled by the device. The diffusivity coefficients $D_{g e l}$, used to derive the TWA concentrations, are a key parameter which should be determined with the highest accuracy to improve method suitability. For this purpose, the $D_{g e l}$ determined in the laboratory experiments (using Equation 4 for the gel stack experiments and Equation 1 for the passive sampler calibration experiments) were used to determine an average value and for evaluating its variability. At a given temperature, the measured $D_{g e l}$ values were not significantly different between the gel stack experiments and the laboratory calibrations despite different calculation methods (Table 1, S2 and S3). Ultimately, the 
observed variability of $D_{g e l}$, similar to the variability on the calculated water concentration, ranged between 0.1 and $0.3 \log$ units depending on the compounds (Table 1).

If the sampling rate of a passive sampler is a function of the compound's hydrophobicity [as most notably for the partitioning based passive samplers for single compound classes (Booij et al. 1998; Belles et al. 2016b)], several publications have demonstrated that the same does not apply for sorption based passive samplers such as POCIS (Carpinteiro et al. 2016). Effectively, uptake kinetics of POCIS devices are controlled by many processes that are not a function of a compound's hydrophobicity, such as the diffusion of compounds into the sorbent pores (Belles et al 2014b). This negates tentative correlations of $\log \mathrm{P}$ with uptake rate. For the present device, the sampler design is specifically adapted for kinetic accumulations controlled by diffusion through the agarose gel which has been demonstrated to be proportional to the diffusivity in water and subsequently to the molecular volume (Fatin-Rouge et al. 2004). Based on this assumption, it is appropriate to evaluate the uptake rate of samplers $\left(D_{g e l}\right)$ from the compounds diffusivity in water and the molecular volume. In addition, it is of primary interest to estimate the $D_{g e l}$ value without performing full calibration experiments under laboratory conditions. For that purpose, the reduced diffusion coefficient relationship between $D_{g e l}$ and $D_{w}\left(\sigma=D_{g e l} / D_{w}\right)$, derived from the results of the laboratory experiments, provides a simple relationship indicating that the expected value of $D_{g e l}$ should reach $62 \%$ of the diffusion coefficient in pure water (Figure 3). For the set of selected compounds, the relationship yields a typical error of 0.2 $\log$ units based on the averaged standard error between the predicted and measured values of $D_{g e l}(0.2$ $\log$ unit error on $\log D_{g e l}$ results in a $14 \%$ error in the calculated water concentrations). Also, this relationship provides an initial estimate of $D_{g e l}$ for dosing additional compounds without the need of specific time consuming calibration experiments. Alternatively, the slice stacking technique could be used to determine a field suitable uptake rate through a laboratory measurement with a contact time of about $1 \mathrm{~h}$. In addition, to avoid a deviation from the calculated water concentration during the field deployment of passive samplers, $D_{g e l}$ determined in the laboratory (usually at 20 or $25^{\circ} \mathrm{C}$ ) requires a correction by using Equation 6 and the temperature measured in the field at least at the deployment and retrieval of the samplers. 
Another aspect to consider when using passive samplers is the detection limit of the method,

especially when monitoring low trace levels. In our study, the amount of compounds detected in the fabrication control and field control samplers were negligible (see section 2.9.) and do not drive the detection limit of the method (Lohmann et al. 2012). In such cases, the detection limit is rather controlled by the analytical detection limit than by the blank level. Owing to the measured $D_{g e l}$ value and an assumed analytical detection limit of $1 \mathrm{ng}$ per sample, we expect that the detection limit of the passive sampler, including all steps of the sampling, would be in the order of $3 \mathrm{ng} \mathrm{L}^{-1}$ for $1 \mathrm{~d}$ of exposure (given $A=78 \mathrm{~cm}^{2} ; \delta=1.2 \mathrm{~mm} ; \log D_{g e l}=-9.2 \mathrm{~m}^{2} \mathrm{~s}^{-1}$ ). This estimated detection limit should be divided by the number of exposure days to provide the final detection limit of a given exposed sampler (i.e. $0.3 \mathrm{ng} \mathrm{L}^{-1}$ for a typical exposure period of $10 \mathrm{~d}$ ).

\subsection{Maximum exposure time for integrative sampling}

To ensure that the passive sampler remains far from equilibrium and to evaluate the maximum exposure time for integrative sampling of the device, the sorption isotherm of compounds between the Strata-X sorbent and water was measured and the distribution constant values $\left(K_{\text {Strata-X }}\right)$ was calculated by fitting the experimental value to the linear sorption model $C_{s}=K_{\text {Strat-X. }} C_{w}$ (where $C_{s}$ refers to the concentration of sorbed compounds). For many of the compounds the linear sorption model deviates from the experimental value, notably for the most polar compounds and the lower contamination levels. This result in lower correlation coefficients between the model and the experimental values reported in Table 1. For these compounds more complex sorption models (such as freundlich, langmuir or dual mode) should improve the predictability of the experimental values (Bäuerlein et al. 2012). However, as a first approach to evaluate the sampler's equilibrium, the adopted linear model is appropriate. To ensure fully integrative sampling, the devices should remain at all times far from equilibrium conditions and subsequently the concentration ratio $C_{s} / C_{w}$ should remain far below the calculated value of $K_{\text {Strata-X. }}$. Combined with equation 1, this assumption could be rearranged as follows: 


$$
t_{\text {max }} \ll \frac{K_{\text {Strata-X }} \delta}{D_{\text {gel }} A}
$$

For each compound, the $t_{\max }$ values below which the exposure period should remain to ensure correct integrative sampling, is reported in Table 1. Atrazine-desethyl is the compound exhibiting the lowest $t_{\max }$ with a value of $4 \mathrm{~d}$. To ensure good device performance, it is reasonable to adopt an exposure period 10 times lower than this threshold. For atrazine-desethyl the threshold is rapidly reached and as suggested by the $K_{\text {Strata-X }}$ dependency with $\log$ P (Figure S1), it is probable that all compounds with a $\log \mathrm{P}$ lower than atrazine-desethyl $(\log \mathrm{P}=1.5)$ are in a similar position. Note that the establishment of an equilibrium state for atrazine-desethyl was not formally observed during the laboratory calibration, most probably due to the underestimation of the $K_{\text {Strata- } X}$ value owing to the nonlinear sorption isotherm. However the equilibrium is probably almost reached as is suggested by the release of atrazine-desethyl during the uncontaminated period (see section 3.2.)

\subsection{Response of passive samplers exposed to a short contamination pulse}

According to Crank et al. (1975), a lag time period is expected in the compounds uptake before the establishment of a steady flow of compounds across the diffusive agarose gel. This may result in a non-linear accumulation curve and delay in integration of a short contamination pulse (Equations 2 and 3). Ultimately, a very short contamination pulse could not be sampled by this type of device. For a common compound with $\log D_{g e l}=-9.2 \mathrm{~m}^{2} \mathrm{~s}^{-1}$ (e.g. galaxolide) sampled by a device with $1.2 \mathrm{~mm}$ diffusive gel thickness, the estimated lag time is about $10 \mathrm{~min}$ (Equation 3). It is noteworthy that similar $t_{l a g}$ are expected for all compounds, because their $D_{g e l}$ are within a narrow range $(7 \mathrm{~min}<$ $t_{\text {lag }}<14 \mathrm{~min}$, Table 1). In addition to the theoretical estimate of $t_{\text {lag }}$, a set of laboratory experiments was conducted to evaluate the effective lag time which represents the minimal period threshold for samplers to sense a contamination event. The results, illustrated in Figure 6, showed that the water concentrations estimated by the device were close to the actual averaged concentration, even for short contamination periods (in the range $5 \mathrm{~min}-320 \mathrm{~min}$ ). In the case of short contamination pulses, the deviations between the passive samplers estimate and the actual TWA water concentration were in the order of the $D_{g e l}$ variability, suggesting that any potential deviation coming from the lag effect for the 
short time would remain lower than the uncertainty on $D_{g e l}$. These results indicate that the calculated water concentration of a contamination pulse longer than $5 \mathrm{~min}$ is accurately recorded by the device without significant deviation. However, the ability of the samplers to detect a short contamination pulse decreases with the pulse duration. Therefore, the shorter the contamination peak, the higher is the detection limit of the method (Figure S2).

\subsection{Field validation}

Using the averaged $D_{g e l}$ determined in laboratory (see section 3.3.), the TWA water concentrations of the selected compounds in the exposure sites were calculated. Because water contamination is expected to vary with time, comparison between the TWA water concentration derived from the passive samplers and the average of conventional spot samples $(n \geq 3)$ may differ. However, by replicating the comparison many times and through different exposure scenarios ( 8 sites were monitored), the accuracy of the approach can be assessed if no systematic deviation is observed between the passive samplers and the grab sample analyses. Punctual differences, for a given compounds at a given site, does not invalidate the developed approach. However, a systematic overestimation or underestimation for a given site or a given compound is critical and poses a potential problem for sampler calibration. The large number of compounds assessed and of sampled sites in this study increase robust evaluation of the comparison. However, selection of larger sets of exposure scenarios, beyond the scope of this study, could improve field validation.. As indicated in Figure 7A and Table S4, no systematic deviation was observed for a given site, suggesting that the device performances are not dependent on the water body properties (e.g. salinity, temperature, hydrodynamic flow). In the only case of the "WWTP" sampling site, water concentrations derived from the passive samplers were overestimated (approximately by a factor 2). Because a contamination pulse is not expected to induce a simultaneous increase of concentration of pollutants belonging to unrelated compound classes (i.e. personal care products, herbicides), the observed systematic overestimation was not attributed to a contamination pulse. Temperature, conductivity and $\mathrm{pH}$, comparable in the "WWTP" samples to the average values measured in the others sampling sites, do not seem to be the cause for this deviation (Table S4). The origin of this overestimation requires 
462 .

further investigations, notably with regard to the dissolved organic matter that is undoubtedly higher in WWTP sampling site and could play an important role in the sampler's performance. Within the exception of propazine, no systematic deviation was observed per compound, indicating that the $D_{g e l}$ determined in the laboratory calibration experiments were suitable for the field exposures (Figure 7B; Table S4). However, such deviation as observed for propazine show that laboratory calibration should be replicated for improving the accuracy of the measured $D_{g e l}$.

\section{CONCLUSIONS}

The interest of using an agarose gel as an anticonvective medium at the exchange surface of the sampler is to precisely define the thickness of the diffusive boundary layer controlling the compounds uptake rate, contrary to the standard configuration of POCIS and polar Chemcatcher. We demonstrate that such diffusive gel passive samplers have a robust uptake rate that allows the use of laboratory calibration data for field monitoring, yielding to relative errors between 30 and $100 \%$ depending on the compounds. With the only exception of atrazine-desethyl, the selected compounds in this study are integratively sampled by the developed device (with compound uptake proportional to the water contamination) which provides quantitative values of the water contamination. In addition, the determination of the compound uptake rates, needed to derive the TWA water contamination from the amount of compounds taken up, is straightforward by using the gel-slice stacking technique.

Diffusive gel-based passive samplers are a very promising approach for the improvement of passive samplers dedicated to comparatively polar compounds dosing. Furthermore, the suitability of the samplers for integrating the concentration fluctuations, even for very short contamination pulses, have been experimentally demonstrated. In the light of these results, such passive samplers should be considered for monitoring simultaneously the TWA water concentrations of exposure periods ranging from a few hours to several days. Furthers study remain necessary for large scale validation of device in filed conditions and through comparative study with other passive sampling techniques. 
489 POTIER G. and D'HELFT M. are acknowledged for the 3D printing of the passive sampler

490 housing. This study was financially supported by the project "Traversière" of the French 491 Institute Carnot M.I.N.E.S.

492 


\section{BIBLIOGRAPHY}

Addeck A., Croes K., Van Langenhove K., Denison M., Elskens M., Baeyens W. Dioxin analysis in water by using a passive sampler and CALUX bioassay. Talanta 2012; 88:73-78.

http://dx.doi.org/10.1016/j.talanta.2011.10.009

Bailly E., Levi Y., Karolak S. Calibration and field evaluation of polar organic chemical integrative sampler (POCIS) for monitoring pharmaceuticals in hospital wastewater. Environmental Pollution 2013; 174:100-105. http://dx.doi.org/10.1016/j.envpol.2012.10.025

Bäuerlein P.S., Mansell J.E., ter Laak T.L., de Voogt P. Sorption Behavior of Charged and Neutral Polar Organic Compounds on Solid Phase Extraction Materials: Which Functional Group Governs Sorption? Environ. Sci. Technol. 2012; 46 (2): 954-961. http://dx.doi.org/10.1021/es203404x

Belles A., Tapie N., Pardon P., Budzinski H. Development of the performance reference compound approach for the calibration of "polar organic chemical integrative sampler" (POCIS). Anal Bioanal Chem. 2014a; 406(4):1131-1140. http://dx.doi.org/10.1007/s00216-013-7297-z

Belles A., Pardon P., Budzinski H. Development of an adapted version of polar organic chemical integrative samplers (POCIS-Nylon). Anal Bioanal Chem. 2014b; 406(4):1099-1110. http://dx.doi.org/10.1007/s00216-013-7286-2

Belles A, Mamindy-Pajany Y, Alary C, Simulation of aromatic polycyclic hydrocarbons remobilization from a river sediment using laboratory experiments supported by passive sampling techniques. Environ Sci Pollut Res Int. 2016a; 23(3):2426-36. http://dx.doi.org/10.1007/s11356-015$\underline{5462-y}$ 
Belles A., Alary C., Mamindy-Pajany Y. Thickness and material selection of polymeric passive samplers for polycyclic aromatic hydrocarbons in water: Which more strongly affects sampler properties? Environ Toxicol Chem. 2016b; 35(7):1708-1717. http://dx.doi.org/10.1002/etc.3326

Booij K., Sleiderink H., Smedes F. Calibrating the uptake kinetics of semipermeable membrane devices using exposure standards. Environ Toxicol Chem. 1998; 17(7):1236-1245.

http://dx.doi.org/10.1002/etc.5620170707

Carpinteiro I., Schopfer A., Estoppey N., Fong C., Grandjean D., de Alencastro L.F. Evaluation of performance reference compounds (PRCs) to monitor emerging polar contaminants by polar organic chemical integrative samplers (POCIS) in rivers. Anal Bioanal Chem. 2016; 408(4):1067-78. http://dx.doi.org/10.1007/s00216-015-9199-8

Chang W-T, Lee C-L, Brimblecombe P, Fang M-D, Chang K-T, Liu J.T. The effects of flow rate and temperature on SPMD measurements of bioavailable PAHs in seawater. Marine Pollution Bulletin 2015; 97(1-2):217-223. http://dx.doi.org/10.1016/j.marpolbul.2015.06.013

Charriau A., Lissalde S., Poulier G., Mazzella N., Buzier R., Guibaud G. Overview of the Chemcatcher ${ }^{\circledR}$ for the passive sampling of various pollutants in aquatic environments Part A: Principles, calibration, preparation and analysis of the sampler. Talanta 2016; 148:556-571. http://dx.doi.org/10.1016/j.talanta.2015.06.064

Chen C.-E., Zhang H., Jones K.C., A novel passive water sampler for in situ sampling of antibiotics. $J$. Environ. Monit., 2012, 14: 1523-1530. http://dx.doi.org/10.1039/c2em30091e

Chen C-E., Zhang H., Ying G-G., Jones K.C., Evidence and Recommendations to Support the Use of a Novel Passive Water Sampler to Quantify Antibiotics in Wastewaters. Environ. Sci. Technol., 2013, 47(23):13587-13593. http://dx.doi.org/10.1021/es402662g 
Chen C.-E., Zhang H., Ying G.-G., Zhou L.-J., Jones K.C., Passive sampling: A cost-effective method for understanding antibiotic fate, behaviour and impact. Environ. Int.,2015, 85: 284-291. http://dx.doi.org/10.1016/j.envint.2015.10.001

Cheng T., Zhao Y., Li X., Lin F., Xu Y., Zhang X., Li Y., Wang R. Computation of Octanol-Water Partition Coefficients by Guiding an Additive Model with Knowledge. J. Chem. Inf. Model. 2007; 47(6):2140-2148. http://dx.doi.org/10.1021/ci700257y

Crank J. 1975. The Mathematics of Diffusion. Oxford University Press Inc., New York, USA.

Fatin-Rouge N., Starchev K., Buffle J. Size Effects on Diffusion Processes within Agarose Gels. Biophys J. 2004; 86(5):2710-2719. http://dx.doi.org/10.1016/S0006-3495(04)74325-8

Fauvelle V., Mazzella N., Belles A., Moreira A., Allan I.J., Budzinski H.Optimization of the polar organic chemical integrative sampler for the sampling of acidic and polar herbicides. Anal Bioanal Chem. 2014; 406(13):3191-3199. http://dx.doi.org/10.1007/s00216-014-7757-0

Garcia-Rodríguez A., Fontàs C., Matamoros V., Almeida M.I.G.S., Cattrall R.W., Kolev S.D. Development of a polymer inclusion membrane-based passive sampler for monitoring of sulfamethoxazole in natural waters. Minimizing the effect of the flow pattern of the aquatic system. Microchemical Journal 2016; 124:175-180. http://dx.doi.org/10.1016/j.microc.2015.08.017

Gourlay-Francé C., Lorgeoux C., Tusseau-Vuillemin M-H. Polycyclic aromatic hydrocarbon sampling in wastewaters using semipermeable membrane devices: Accuracy of time-weighted average concentration estimations of truly dissolved compounds. Chemosphere 2008; 73(8):1194-1200. http://dx.doi.org/10.1016/j.chemosphere.2008.07.049 
Harman C., Allan IJ, Bäuerlein PS, The Challenge of Exposure Correction for Polar Passive

Samplers-The PRC and the POCIS. Environ. Sci. Technol. 2011; 45(21):9120-9121.

http://dx.doi.org/10.1021/es2033789

Hayduk W., Laudie H. Prediction of Diffusion Coefficients for Non-Electrolytes in Dilute Aqueous Solutions AIChE Journal 1974; 20(3):611-615. http://dx.doi.org/10.1002/aic.690200329

Huckins J., Petty J., Booij K. Monitors of Organic Chemicals in the Environment: Semipermeable Membrane Devices. Springer, New York, 2006, NY, USA.

Johnson E.M., Berk D.A., Rakesh A., Jain K., Deen W.M. Hindered Diffusion in Agarose Gels: Test of Effective Medium Model. Biophys J. 1996; 70(2):1017-1023. http://dx.doi.org/10.1016/S0006$\underline{3495(96) 79645-5}$

Li H., Vermeirssen E.L., Helm P.A., Metcalfe C.D., Controlled field evaluation of water flow rate effects on sampling polar organic compounds using polar organic chemical integrative samplers. Environ Toxicol Chem. 2010, 29(11):2461-2469. http://dx.doi.org/10.1002/etc.305

Liu H-H., Wong C.S. Zeng E.Y. Recognizing the Limitations of Performance Reference Compound (PRC)-Calibration Technique in Passive Water Sampling. Environ. Sci. Technol., 2013, 47(18):1010410105. http://dx.doi.org/10.1021/es403353d

Lohmann R, Booij K, Smedes F, Vrana B. Use of passive sampling devices for monitoring and compliance checking of POP concentrations in water. Environ Sci Pollut Res. 2012, 19:1885-95. http://dx.doi.org/10.1007/s11356-012-0748-9 
O’Brien D., Komarova T., Mueller J.F. Determination of deployment specific chemical uptake rates for SPMD and PDMS using a passive flow monitor. Marine Pollution Bulletin, 2012; 64(5):10051011. http://dx.doi.org/10.1016/j.marpolbul.2012.02.004

Partington, J.: An advanced treatise on physical chemistry, Longmans Green, London, New York, 1949.

Pluen A., Netti P.A., Jain R.K., Berk D.A. Diffusion of Macromolecules in Agarose Gels: Comparison of Linear and Globular Configurations. Biophys J. 1999; 77(1):542-552. http://dx.doi.org/10.1016/S0006-3495(99)76911-0

Rusina T., Smedes F., Klánová J. Diffusion coefficients of polychlorinated biphenyls and polycyclic aromatic hydrocarbons in some polymers. Journal of applied polymer science, 2010; 116(3)18031810. http://dx.doi.org/10.1002/app.31704

Sathyanarayana M. Upadrashta, Bert O. Häglund, Lars-Olof Sundelöf. Diffusion and Concentration Profiles of Drugs in Gels. Journal of pharmaceutical sciences 1993; 82(11):1094-1098. http://dx.doi.org/10.1002/jps.2600821106

Thompson J.M., Hsieh C.H., Luthy R.G., Modeling uptake of hydrophobic organic contaminants into polyethylene passive samplers. Environ Sci Technol. 2015; 49(4):2270-2277. http://dx.doi.org/10.1021/es504442s

Vermeirssen E.L.M., Dietschweiler C., Escher B.I., van der Voet J., Hollender J. Transfer Kinetics of Polar Organic Compounds over Polyethersulfone Membranes in the Passive Samplers Pocis and Chemcatcher. Environ. Sci. Technol. 2012; 46(12)6759-6766. http://dx.doi.org/10.1021/es3007854 
Vrana B., Smedes F., Prokeš R., Loos R., Mazzella N., Miege C., Budzinski H., Vermeirssen E.,

Ocelka T., Gravell A., Kaserzon S. An interlaboratory study on passive sampling of emerging water pollutants. TrAC Trends in Analytical Chemistry, 2016; 76:153-165.

http://dx.doi.org/10.1016/j.trac.2015.10.013 
Table 1: Agarose gel diffusion coefficient $\left(\log D_{g e l}\right)$ determined in laboratory at $4{ }^{\circ} \mathrm{C}$ and $20{ }^{\circ} \mathrm{C}$ and apparent activation energy $\left(\mathrm{Ea} ; \mathrm{kJ} \mathrm{mol}^{-1}\right)$ of compounds diffusion within the gel.

\begin{tabular}{lcc|cc|c}
\hline & $\begin{array}{c}\log \mathrm{P} \\
\mathrm{a}\end{array}$ & $\begin{array}{c}\mathrm{Log} D_{w} \\
\left(\mathrm{~m}^{2} \mathrm{~s}^{-1}\right)^{\mathrm{b}}\end{array}$ & $\begin{array}{c}\log D_{g e l}{ }^{4} \mathrm{C} \\
\left(\mathrm{m}^{2} \mathrm{~s}^{-1}\right)\end{array}$ & $\begin{array}{c}\log D_{g e l} 20^{\circ} \mathrm{C} \\
\left(\mathrm{m}^{2} \mathrm{~s}^{-1}\right)\end{array}$ & $\begin{array}{c}E a \\
\left(\mathrm{~kJ} \mathrm{~mol}^{-1}\right)\end{array}$ \\
\hline Atrazine & 2.6 & -9.27 & $-10.0 \pm 0.1$ & $-9.4 \pm 0.1$ & 57 \\
Atrazine-desethyl & 1.5 & -9.21 & $-9.8 \pm 0.2$ & $-9.4 \pm 0.1$ & 42 \\
Benzophenone & 3.4 & -9.25 & $-9.7 \pm 0.2$ & $-9.5 \pm 0.1$ & 27 \\
Diflufenican & 4.6 & -9.42 & $-10.1 \pm 0.2$ & $-9.5 \pm 0.1$ & 57 \\
Galaxolide & 4.8 & -9.36 & $-10.3 \pm 0.2$ & $-9.5 \pm 0.1$ & 74 \\
Irgarol & 3.9 & -9.32 & $-9.9 \pm 0.1$ & $-9.5 \pm 0.1$ & 46 \\
Lilial & 3.9 & -9.31 & $-10.0 \pm 0.2$ & $-9.5 \pm 0.1$ & 46 \\
Metazachlore & 2.7 & -9.33 & $-10.1 \pm 0.1$ & $-9.4 \pm 0.1$ & 61 \\
Metolachlore & 3.1 & -9.36 & $-9.9 \pm 0.2$ & $-9.4 \pm 0.1$ & 49 \\
Octicizer & 6.3 & -9.44 & $-10.0 \pm 0.1$ & $-9.5 \pm 0.2$ & 45 \\
Propazine & 2.9 & -9.29 & $-10.1 \pm 0.1$ & $-9.5 \pm 0.1$ & 57 \\
Simazine & 2.2 & -9.24 & $-9.8 \pm 0.1$ & $-9.3 \pm 0.1$ & 52 \\
Tonalid & 5.3 & -9.36 & $-10.1 \pm 0.1$ & $-9.6 \pm 0.1$ & 48 \\
Tri(n-butyl)phosphate & 3.7 & -9.22 & $-9.8 \pm 0.3$ & $-9.6 \pm 0.3$ & 27 \\
Triisobutyl phosphate & 3.0 & -9.22 & $-9.8 \pm 0.3$ & $-9.6 \pm 0.3$ & 21 \\
Tris(phenyl)phosphate & 4.6 & -9.38 & $-10.0 \pm 0.1$ & $-9.6 \pm 0.1$ & 42 \\
\hline
\end{tabular}



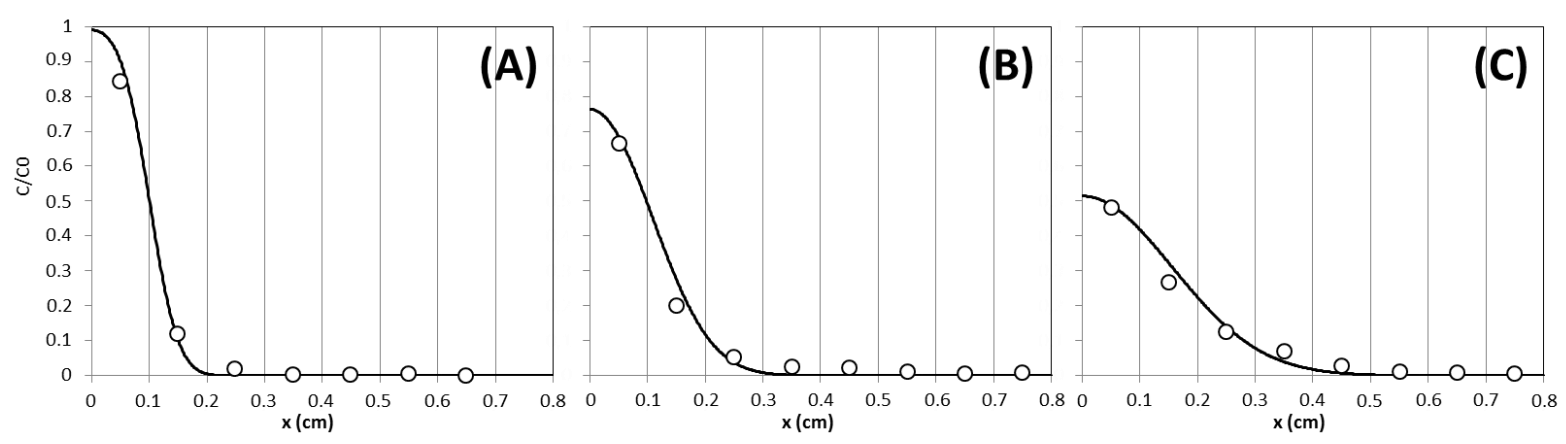

Figure 1 Concentration distribution of galaxolide in agarose gel stack after $5 \mathrm{~min}$ (A), $20 \mathrm{~min}$ (B) and $2 \mathrm{~h}(\mathrm{C})$ of contact time. Black curves represent the fit of Equation 4 with $D_{\text {gel }}$ used as the adjustment factor. Vertical lines represent the boundaries between two gel slabs of the stack.

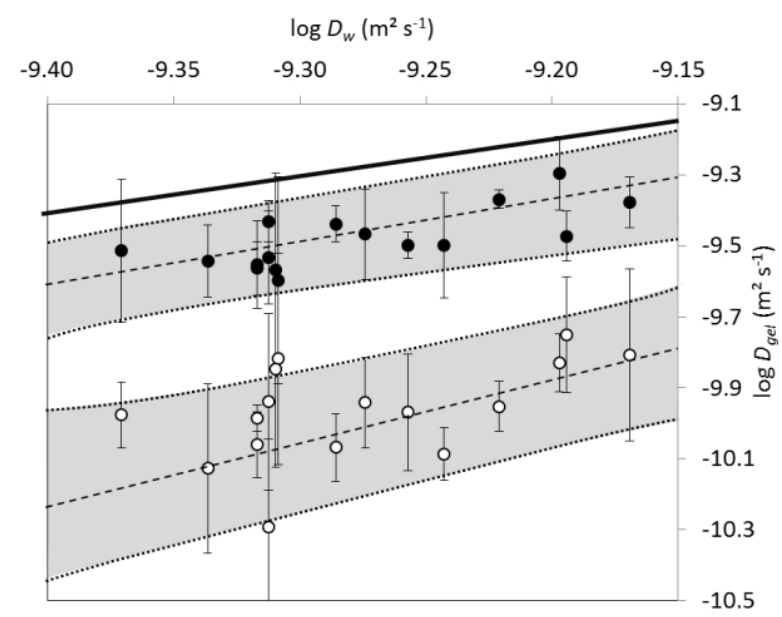

Figure 2 double logarithmic scaled plots $D_{g e l}$ against $D_{w}$. Filled symbols refer to the average $D_{g e l}$ determined at $20{ }^{\circ} \mathrm{C}$, and the open symbols refer to the average $D_{g e l}$ determined at $4{ }^{\circ} \mathrm{C}$. Full lines refer to the diffusion coefficient in water estimated following Hayduk and Laudie (1974) at $20{ }^{\circ} \mathrm{C}(1: 1$ agreement line). Dashed line represents the linear regression of each data set; the dotted lines represent the $95 \%$ confidence interval. 


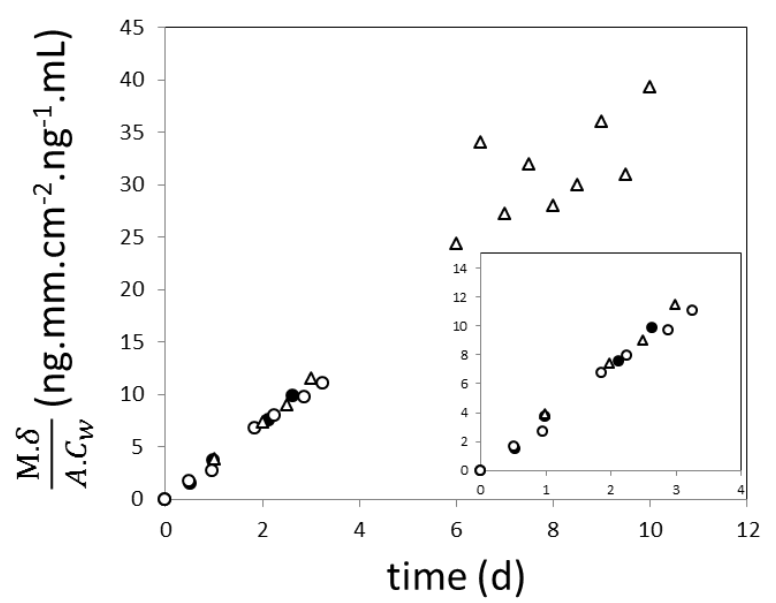

Figure 3 Uptake of atrazine in both experiments simulating 2 water flow rates and contamination levels. Triangles refer to the strong water flow and constant water contamination experiment. Circles refer to the variable water contamination experiment (filled symbols refer to the first contamination period and open symbols to the second contamination period). For a direct comparison, the accumulation curve [sampled amount $(M)$ multiplied by the gel thickness $(\delta)$ and divided by the sampling area $(A)]$ is normalized by the water contamination level $\left(C_{w}\right)$. The inset provides a zoomed in view of the short time.

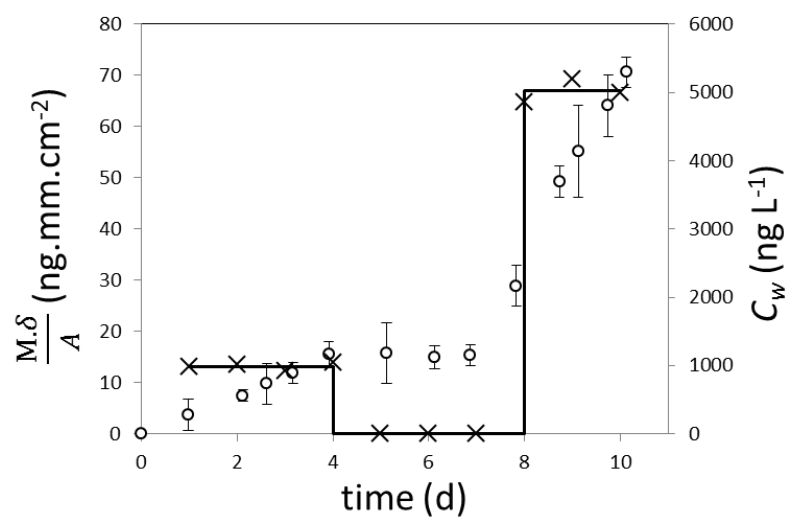

Figure 4 Uptake of atrazine during the discontinuous water contamination simulation. Left-axis refers to the accumulated amount of compounds. Right-axis refers to the aqueous concentration. Full line represents the nominal water concentration, cross symbols are the measured water contaminations and circles are the amount of compounds sampled by the device. 


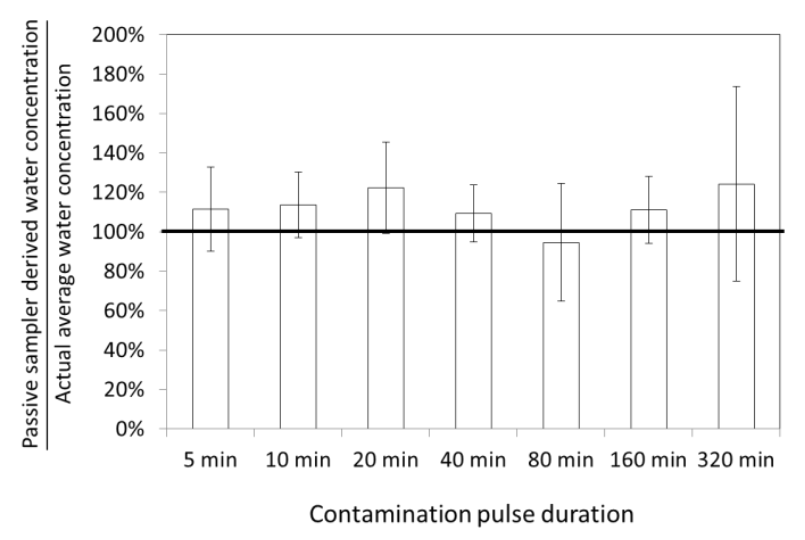

Figure 5 Comparison between the passive samplers derived water concentration and the actual average water contamination for the various simulated contamination pulses. Contamination pulse levels and durations are selected in order to expose all devices to the same TWA water contamination. The results are expressed as the average of all the selected compounds. Error bars refer to the standard deviation $(n=16)$.
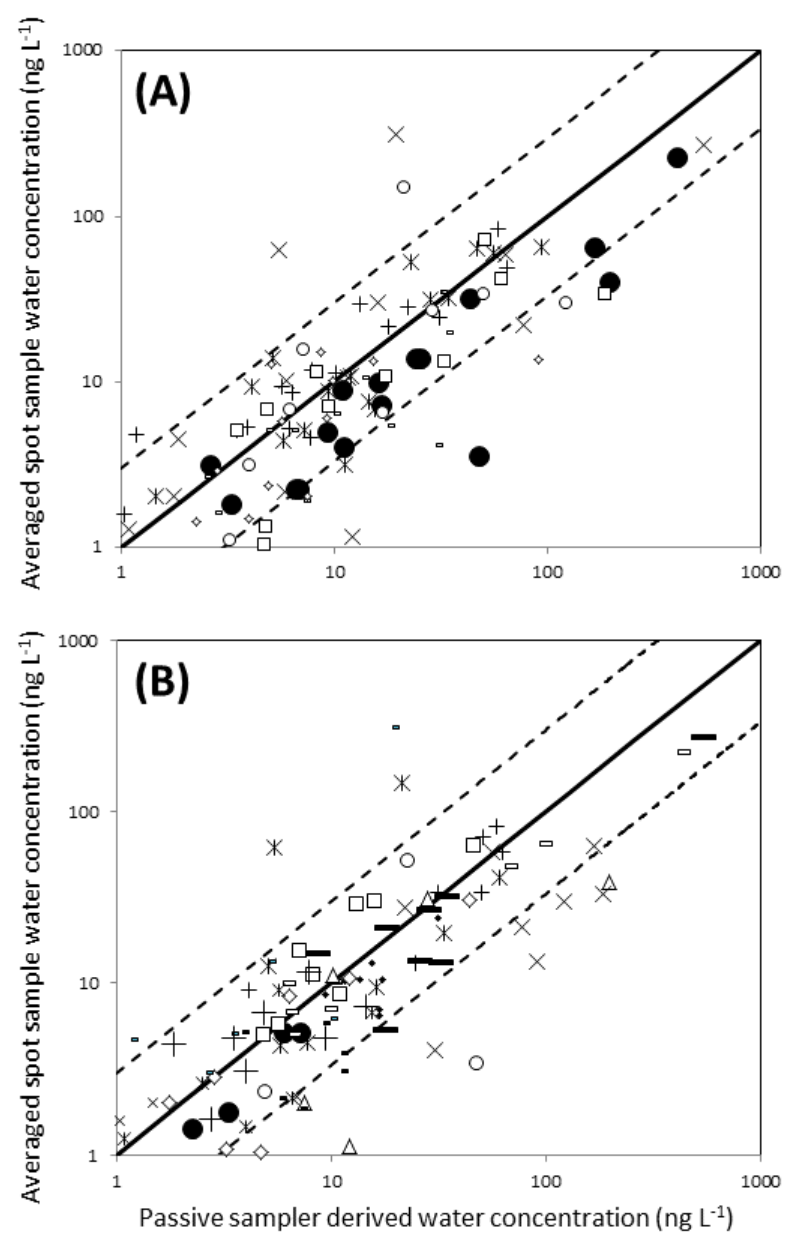
Figure 6 Average spot sampling measured water concentrations against the passive sampler derived water concentrations. In part (A), the different markers indicate different exposure sites (filled circles represent the WWTP sampling site which is the only site to show a systematic deviation). In part (B), the same date is plotted with symbols indicating different compounds (filled circles represent propazine which is the only compound to show a systematic deviation). Full lines refer to the 1:1 agreement line and dotted lines to the factor 3 deviation lines. 
Self-archived accepted manuscript for Plymouth's research repository - published article available on Talanta http://www.sciencedirect.com/science/article/pii/S0039914016309523 